\title{
Determination of total body water by a simple and rapid mass spectrometric method.
}

Citation for published version (APA):

van Kreel, B. K., de Vegt, F., Meers, M., Wagenmakers, A. J. M., Westerterp, K. R., \& Coward, A. (1996).

Determination of total body water by a simple and rapid mass spectrometric method. Journal of Mass Spectrometry, 31(1), 108-111. https://doi.org/10.1002/(SICI)1096-9888(199601)31:1<108::AIDJMS279>3.0.CO;2-M

Document status and date:

Published: 01/01/1996

DOI:

10.1002/(SICI)1096-9888(199601)31:1<108::AID-JMS279>3.0.CO;2-M

Document Version:

Publisher's PDF, also known as Version of record

Document license:

Taverne

Please check the document version of this publication:

- A submitted manuscript is the version of the article upon submission and before peer-review. There can be important differences between the submitted version and the official published version of record.

People interested in the research are advised to contact the author for the final version of the publication, or visit the DOI to the publisher's website.

- The final author version and the galley proof are versions of the publication after peer review.

- The final published version features the final layout of the paper including the volume, issue and page numbers.

Link to publication

\footnotetext{
General rights rights.

- You may freely distribute the URL identifying the publication in the public portal. please follow below link for the End User Agreement:

www.umlib.nl/taverne-license

Take down policy

If you believe that this document breaches copyright please contact us at:

repository@maastrichtuniversity.nl

providing details and we will investigate your claim.
}

Copyright and moral rights for the publications made accessible in the public portal are retained by the authors and/or other copyright owners and it is a condition of accessing publications that users recognise and abide by the legal requirements associated with these

- Users may download and print one copy of any publication from the public portal for the purpose of private study or research.

- You may not further distribute the material or use it for any profit-making activity or commercial gain

If the publication is distributed under the terms of Article $25 \mathrm{fa}$ of the Dutch Copyright Act, indicated by the "Taverne" license above, 


\title{
Determination of Total Body Water by a Simple and Rapid Mass Spectrometric Method
}

\author{
B. K. Van Kreel, ${ }^{1 *}$ F. Van der Vegt, ${ }^{1}$ M. Meers, ${ }^{1}$ T. Wagenmakers, ${ }^{1}$ K. Westerterp ${ }^{3}$ and A. Coward ${ }^{2}$ \\ ${ }^{1}$ Stable Isotope Research Centre, University Hospital Maastricht, Dept. of Clinical Chemistry, P.O. Box 5800, 6202 AZ \\ Maastricht, The Netherlands \\ ${ }^{2}$ Medical Research Council, Dunn Nutrition Centre, Milton Road, Cambridge, CB4 1XJ United Kingdom \\ ${ }^{3}$ Human Biology Department, University of Limburg, P.O. Box 616, 6200 MD Maastricht, The Netherlands
}

\begin{abstract}
A rapid and inexpensive method was developed to determine deuterium enrichment in body fluids. This is achieved by converting water into acetylene. To vacutainer tubes a small amount of calcium carbide is added. The tubes are evacuated and $25 \mu \mathrm{l}$ of sample are injected through the stopper. The reaction takes place spontaneously at room temperature in a few seconds. Enrichment at mass 27 compared with mass 26 can be determined by continuous flow isotope ratio mass spectrometry without any interference from the carrier gas helium. A series of $\mathrm{D}_{2} \mathrm{O}$ samples diluted with increasing amounts of $\mathrm{H}_{2} \mathrm{O}$ is prepared at the time of measurement of the biological samples and the measured ratios are used to calculate the isotope dilution of the unknown. The relative error of the method is $1.6 \%$ when a dose of $25 \mathrm{ml} \mathrm{kg}^{-1}$ is administered to the patient. The method was compared with two different methods in use in other laboratories, hy a published method The means of the differences were -0.1 and $0.08 \mathrm{l}$, respectively, with standard deviations of 0.63 and 3.0.
\end{abstract}

KEYWORDS: $\mathrm{D}_{2} \mathrm{O}$; total body water; mass spectrometer

\section{INTRODUCTION}

The measurement of body cell mass provides an accurate estimation of the nutritional state of severely undernourished patients. ${ }^{1}$ In practice, a method to accomplish this is to measure total body water (TBW) and extracellular volume (ECV). The method of choice for the determination of TBW is $\mathrm{D}_{2} \mathrm{O}$ dilution. Several methods are in use that convert $\mathrm{H}_{2} \mathrm{O}$ into $\mathrm{H}_{2}$ gas on-line in a reduction furnace either using a timeconsuming off-line method ${ }^{2}$ or in an integrated preparation and measurement system such as the Aqua-Sira. ${ }^{3}$ The use of a reduction furnace leads to memory effects and requires up to ten replicate sample injections for reliable results. ${ }^{4}$ It further requires a dedicated instrument. The reduction of $\mathrm{H}_{2} \mathrm{O}$ to $\mathrm{H}_{2}$ requires special equipment and high temperatures. The reducing agent is often difficult to obtain. ${ }^{5}$ In all Coplan methods that use conversion of water to hydrogen it is important that the reaction goes to completion with the equilibrium gas enrichment determined by a fractionation factor. Recently a new method has been published ${ }^{6}$ that is both rapid and labour saving. This method uses a platinum catalyst to increase the rate of deuterium exchange between $\mathrm{H}_{2} \mathrm{O}$ gas and $\mathrm{H}_{2}$ gas.

In our laboratories we have access to instrumentation for gas chromatography/continuous flow isotope ratio mass spectrometry (GC/CF-IRMS) which allows themeasurement of isotope ratios in gas molecules that are transported to the IRMS unit in a stream of helium. The actual measurement of the isotope ratios takes place in a few seconds and allows rapid sample processing.

* Author to whom correspondence should be addressed.
A limitation of the GC/CF-IRMS technique is that the deuterium enrichment in hydrogen gas cannot easily be measured owing to the presence of excess helium carrier gas. When helium is present as the carrier gas ions within an $\mathrm{m} / \mathrm{z}$ ratio of 4 scatter into the detector $m / z=3$.

We therefore decided to investigate whether we could make $\mathrm{H}_{2} \mathrm{O}$ react with carbide to form acetylene gas, and measure the deuterium enrichment of $\mathrm{H}_{2} \mathrm{O}$ as the mass $27 / 26$ ratio of acetylene $\left(\mathrm{C}_{2} \mathrm{H}\right)$ versus $\left(\mathrm{C}_{2} \mathrm{H}_{2}\right)$ after injection of aliquots of acetylene gas into the GC/CFIRMS system. The acetylene is generated off-line by injecting a sample of water into sealed tubes containing calcium carbide. Because we do not have acetylene gas with accurately know isotope composition at our disposal, no absolute enrichments can be measured, and samples with unknown amounts of $\mathrm{D}_{2} \mathrm{O}$ are compared with standards.

\section{EXPERIMENTAL}

\section{Preparation of the sample}

Siliconized vacutainer tubes (Becton Dickinson, Rutherford, NJ, USA) were uncapped and $350 \mathrm{mg}(5.4 \mathrm{mmol})$ of $\mathrm{CaC}_{2}\left(M_{\mathrm{r}}\right.$ 64) (80\% pure, obtained from Aldrich) were placed at the bottom of the tubes. The tubes were recapped and a hypodermic needle $(25 \times 0.6 \mathrm{~mm}$ monoject needle) was used to perforate the rubber stoppers. A rotary vane pump was used to evacuate the vacutainer tubes for $30 \mathrm{~s}$ to a total pressure of $0.01 \mathrm{~atm}$. A $25 \mu \mathrm{l}$ $(1.4 \mathrm{mmol})$ water sample was then injected through the stopper directly on to the calcium carbide. This was done in duplicate. The tubes were left to cool for $5 \mathrm{~min}$ 
while being shaken. From each sample $25 \mu \mathrm{l}$ of gas were subsequently injected in duplicate into the GC/CFIRMS system at 2 min intervals. The mass 27 to 26 ratio was determined and the mean value of four determinations was used to calculate the tracer/tracee ratio, defined as the mass $27 / 26$ ratio of the sample minus the ratio of the blank. ${ }^{7}$ The dilution was then calculated by inserting this ratio into the regression equation obtained from the standards.

The protocol for the determination of TBW in patients was as follows: $30 \mathrm{~min}$ before time zero the patient did not eat or drink. At zero time $(T=0)$ the patient received a plug of dental cotton-wool that was dried overnight at $100^{\circ} \mathrm{C}$ and kept in a gas-tight tube until used. After chewing for about $1 \mathrm{~min}$, the plug was placed in a special centrifuge tube (Salivette, Sarsted) and the saliva obtained after centrifugation was kept in a stoppered glass vial until analysis (sample $T=0$ ). Subsequently, the patient drank $25 \mathrm{ml}$ of deuterated water (Sigma D 4501, 99.9\%), and thereafter $100 \mathrm{ml}$ of tap water to flush the mouth. The patient was then allowed to eat and drink as normal. After $3.5 \mathrm{~h}$ no eating and drinking were allowed, and 30 min later the second saliva sample was taken $(T=4)$.

The mass $27 / 26$ ratio of the blank $(T=0)$ was subtracted from the ratio measurement at $(T=4)$ (enriched sample). This corrected for the possible effect of protonation of the $m / z 26$ ion within the MS source.

\section{Equipment}

The mass spectrometer was a Finnigan MAT 252 for CF-IRMS), coupled to a Hewlett-Packard Model 5840 A gas chromatograph with a gas separation column attached (Poroplot Q, Chrompack). The outlet of the gas chromatograph was connected directly to the mass spectrometer via an open split, which allowed $10 \%$ of the column flow to enter the mass spectrometer.

Typical operating parameters for the mass spectrometer were as follows: ion source pressure, $6 \times 10^{-6}$ mbar (i bar $=10^{5} \mathrm{~Pa}$ ); high voltage, $10 \mathrm{kV}$; and emission, $0.270 \mathrm{~mA}$. The operating parameters for the gas chromatograph were as follows: column pressure, $18 \mathrm{psi}$ $(1 \mathrm{psi}=6.895 \mathrm{kPa})$; column flow, $0.3 \mathrm{ml} \mathrm{min}{ }^{-1}$; split (at injection port), $4 \mathrm{ml} \mathrm{min}{ }^{-1}$; injector and column temperatures, $25^{\circ} \mathrm{C}$; carrier gas, helium.

The instrumentation used was equipped with six Faraday cups. They were positioned such that masses 28,29 and 30 of nitrogen and masses 44,45 and 46 of $\mathrm{CO}_{2}$ could be measured. One cup that can be used to measure $\mathrm{CO}_{2}$ at mass 64 was repositioned to measure the acetylene mass 26 .

\section{RESULTS}

The optimum conditions for sample handling were investigated together with the optimum instrument setting to produce mass $27 / 26$ ratio values with small coefficients of variation (CV).

\section{Optimum sample size}

A series of vacutainers were prepared with a constant amount of carbide of $350 \mathrm{mg}(5.4 \mathrm{mmol})$. The tubes were evacuated as described under Experimental and increasing volumes of water were injected. After $1 \mathrm{~h}$ the pressure in the tube was measured with a needle pressure-measuring device. However, the pressure still increased slightly after the $1 \mathrm{~h}$ period. At pressures above $1.6 \mathrm{~atm}$ the stoppers of the vacutainer tubes were ejected spontaneously. This occurred at a sample volume of $60 \mu \mathrm{l}$. A pressure of $1 \mathrm{~atm}$ measured after $1 \mathrm{~h}$ was obtained at a value of $30 \mu \mathrm{l}$ (Fig. 1).

The injection volume chosen should produce a pressure between 1.0 and $1.6 \mathrm{~atm}$ because at high pressure there is a risk of ejection of the stopper. Pressures below $1 \mathrm{~atm}$ should also be avoided because of the possibility of leakage of moisture from the atmosphere into the tubes that still contain the carbide. An injection volume of $25 \mu \mathrm{l}(1.4 \mathrm{mmol})$ was chosen; theoretically this should produce a pressure of $1.6 \mathrm{~atm}$. Hence it seems that the yield is less than $100 \%$ during $1 \mathrm{~h}$ of contact between the water and carbide. A possible explanation could be that part of the water evaporates as a result of heat development and condenses on the tube wall. This water will evaporate again and react with the carbide. As a vacutainer can withstand a pressure of $1.6 \mathrm{~atm}$, this is the maximum pressure that a sample of $25 \mu 1$ can develop. As shown in Table 1 , incomplete reaction will not influence the results obtained.

\section{Stability of the samples after reaction}

Three healthy volunteers, denoted $\mathbf{D}, \mathbf{F}$ and $\mathbf{M}$, were used to determine the TBW. Saliva was collected as indicated under Experimental

A standard dilution curve was prepared (dilution from $1: 1000$ to $1: 8000$ ) and $25 \mu 1$ were injected into vacutainer tubes containing $0.3 \mathrm{~g}$ of $\mathrm{CaC}_{2}$. The saliva samples were treated similarly. From these tubes $25 \mu \mathrm{l}$ of gas were injected into the GC/CF-IRMS system. The

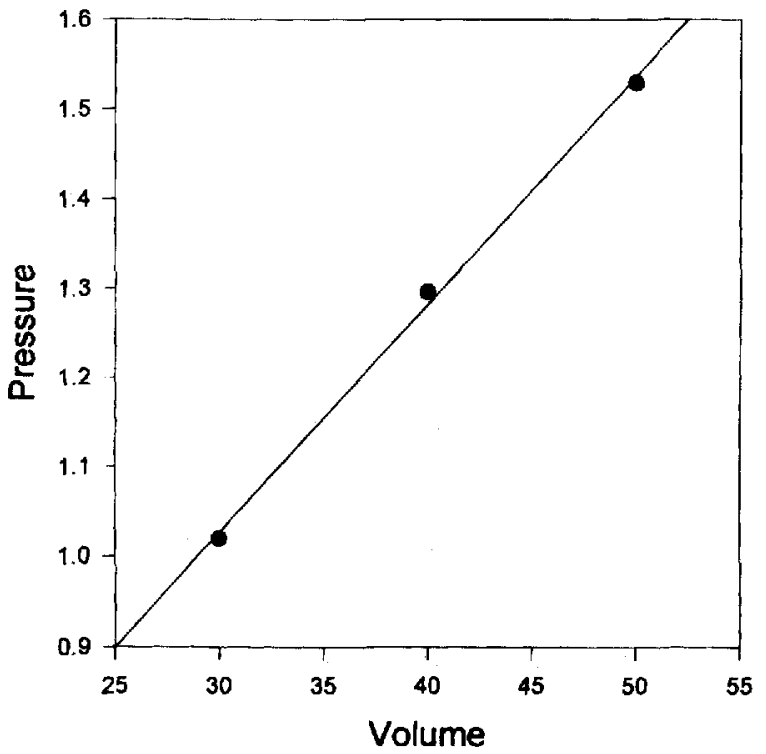

Figure 1. Pressure in the tubes filled with $300 \mathrm{mg}$ of carbide after injection of various amounts of water. Ordinate, pressure in atm abscissa, volume injected in $\mu$. 
Table 1. Results of the measurement of different standard curves (series A, B, etc.)"

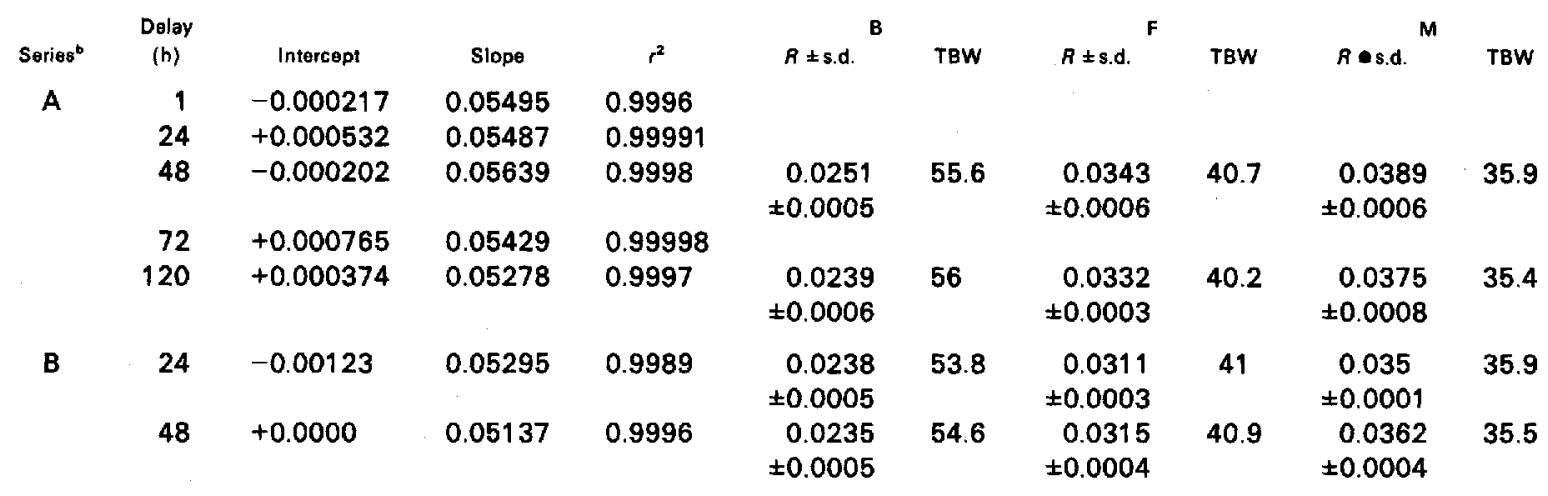

- The delay indicates the time elapsed from the moment the sample was injected into the vacutainer tube until the analysis by IRMS. The mass $27 / 26$ ratio is the dependent variable and the dilution is the independent variable. $B, F$ and $M$ represent the mass $27 / 26$ values $(R)$ and the TBW values of the volunteers.

mean value of the mass $27 / 26$ ratio of the standards was used to construct the standard line. The mean values and standard deviations of the saliva samples and the slope and intercept of the accompanying standard line are given in Table 1.

We also examined how long the vacutainers containing the acetylene could be stored before the measured mass $27 / 26$ ratio began to change. To do so, the vacutainers containing the $\mathrm{C}_{2} \mathrm{HD}$ gas were re-used to determine the mass $27 / 26$ ratio after some time had elapsed (series A, Table 1). The same saliva and standard samples were injected a second time into vacutainers and analysed after 24 and $48 \mathrm{~h}$. The results are given as series B in Table 1.

A typical standard dilution line is presented in Fig. 2. Because dilution of the sample is the variable calculated from the measured mass $27 / 26$ ratio, it is shown as the dependent variable. The results presented in Table 1 indicate that as time elapses the slope tends to decrease, probably as a result of moisture that diffuses from the outside into the vacutainer (note: in this case, the mass $27 / 26$ ratio is considered the dependent variable). This could be the result of leakage.

From these measurements, it can also be concluded that when the dilution is measured using the standards that belong to a particular set of samples, identical TBW values are obtained even when the tubes filled with acetylene had been stored for 5 days $(120 \mathrm{~h}$ ). From the results in Table 1, it can also be calculated that the within-subject relative error is $1.6 \%$.

\section{Contribution of water vapour in the air}

Six vacutainers were filled with $300 \mathrm{mg}$ of carbide, stoppered and evacuated. Pure helium was then injected until a pressure of $1 \mathrm{~atm}$ was reached, then $100 \mu$ of gas was injected into the GC/CF-IRMS system.

The mean area of $\mathrm{C}_{2} \mathrm{H}_{2}$ measured was 0.7 . A typical area for a TBW measurement is 44 with $25 \mu$ injected into the mass spectrometer. Hence the background contribution is only $0.7 /(44 \times 4) \approx 0.4 \%$. Because this error occurs in both terms that are subtracted, this error will almost disappear.

\section{Validation of the method}

The present method was compared with two different methods. The present method is called (a). The other methods are (b) using the Aqua-Sira ${ }^{8}$ and (c) where use is made of exchange between $H$ in gas and $H$ in water as described by Coplan et al. ${ }^{6}$ To compare method (a) with method (b), eight volunteers received a dose of $\mathrm{D}_{2} \mathrm{O}$. At $T=0$ samples were taken and again after $4 \mathrm{~h}$. This procedure was repeated after 2 weeks. TBW was determined for all volunteers with the two methods. In order to compare method (a) with method (c), one volunteer received a dose at $T=0$ and samples were taken at $T=2,4,6,8$ and $10 \mathrm{~h}$. Sampling was continued for 9 days (one sample per day). The apparent

\section{Standard Line}

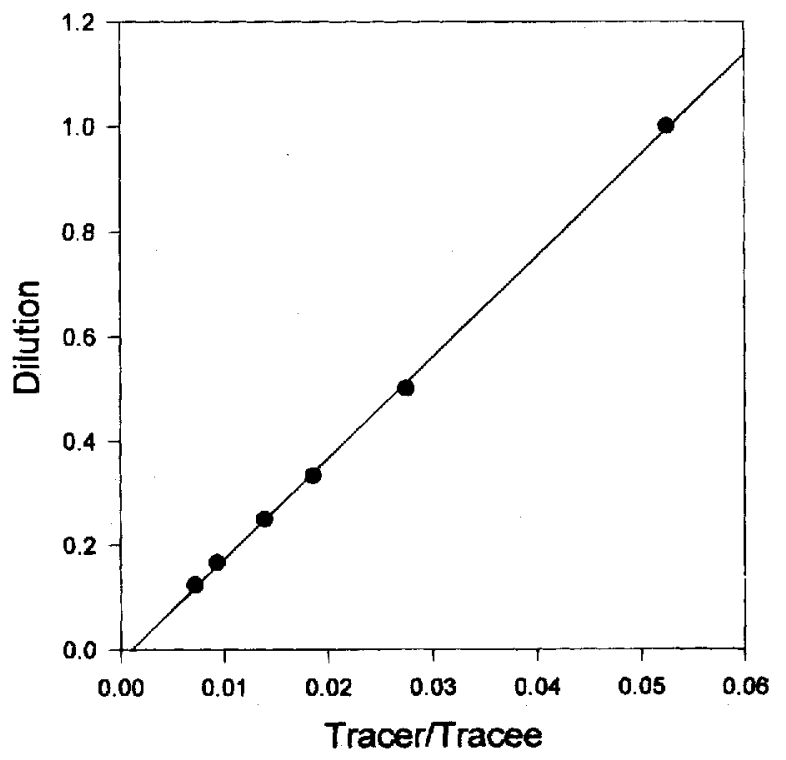

Figure 2. Standard dilution curve. Ordinate, dilution (factor $10^{-3}$ has been left out); abscissa, tracer/tracee ratio $\left(R, 27 / 26-R_{\mathrm{bl}}\right.$ 27/26). Note: compared with the results in Table 1 , dependent and independent variables are interchanged, because normally dilution is calculated (from the regression equation) from the measured ratio. 
measuring agreement methods $a$ and $b$

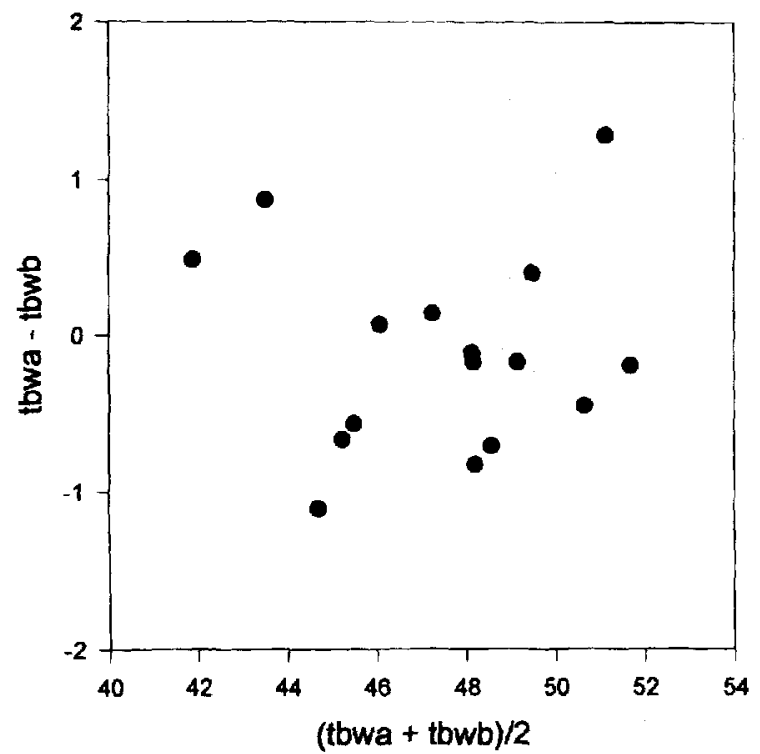

Figure 3. Agreement between methods (a) and (b). Abscissa, differences in TBW values of samples measured with the AquaSira method and our method; ordinate, mean values for samples.

\section{measuring agreement methods a and c}

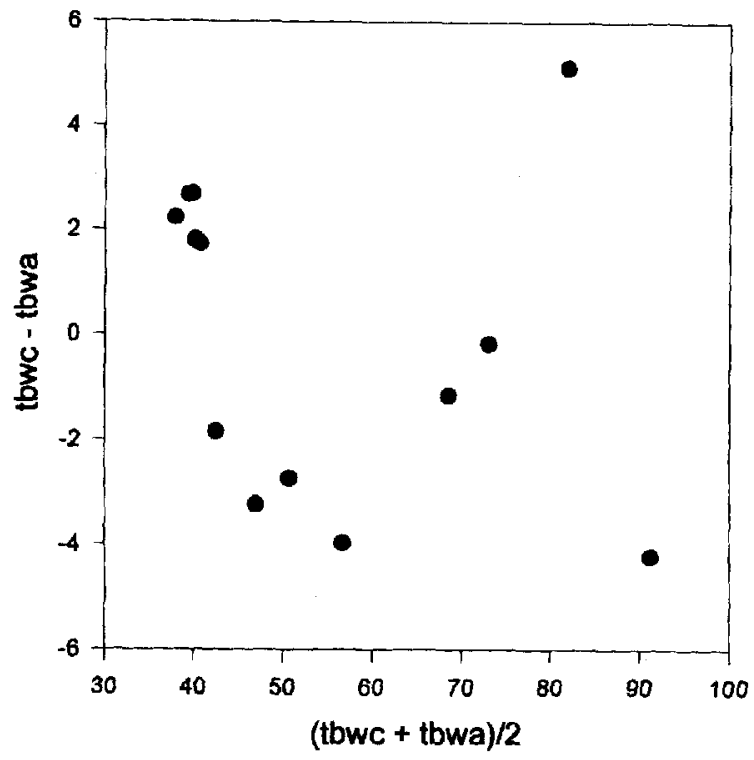

Figure 4. Agreement between methods (a) and (c). Abscissa, differences in apparent TBW values of samples measured with Coplan et af.'s method and our method; ordinate, mean values for the samples.
TBWs (dose of pure $\mathrm{D}_{2} \mathrm{O} \mathrm{mL} /$ dilution) were determined using both methods.

The data were analysed using the method suggested by Bland and Altman. ${ }^{9}$ The results pertaining to the comparison of our method with the Aqua-Sira are given in Fig 3. The mean of the differences is -0.101 , with a standard deviation of $0.631(1.2 \%)$. Comparison with the method of Coplan et al. is given in Fig 4. The mean of the differences is $-0.08 \mathrm{l}$, with a standard deviation of 3.01 .

\section{DISCUSSION}

The overall conclusion reached from this series of experiments is that TBW can be determined using a continuous flow isotope ratio mass spectrometer. With the proposed method an accuracy of $1.6 \%$ is obtained. The use of standards for each batch of samples is necessary, as shown in Table 1, because of a slight drift in the slope and intercept of the tracer dilution line with time. The method requires an analysis time of $2 \mathrm{~min}$ per sample and can easily be automated because the samples are stable for at least 5 days. The value obtained after $48 \mathrm{~h}$ is identical with that obtained when the sample is analysed again after $120 \mathrm{~h}$ (series A). The TBW value obtained for volunteer $B$ in series $C(581)$ is the only exception, but has an exceptionally high standard deviation $(0.0010 \mathrm{l})$ which is twice the value obtained for the other samples. An explanation cannot be given but in practice an analysis with a high standard deviation needs to be repeated. When the present method is compared with two different methods for measuring $\mathrm{D}_{2} \mathrm{O}$ enrichment and the differences of both methods are related to the mean, ${ }^{9}$ the mean of the differences is very small for both methods compared with ours. This indicates that there is no bias. The Aqua-Sira method compared with our method also gives an acceptable standard deviation of the differences $(1.2 \%)$. The comparison of our method with the method of Coplan et al. gives a standard deviation of $3.0 \mathrm{l}$, but the apparent TBW values increase from 40 to 901 and, as can be seen from Fig 4, the error tends to increase with dilution of the samples (high TBW values indicate high dilution).

In conclusion, the $\mathrm{D}_{2} \mathrm{O}$ method presented here is patient-friendly and fast. When combined with the determination of extracellular (bromide) space, ${ }^{10}$ it can provide the clinician with valuable information about body composition. ${ }^{1}$

\section{REFERENCES}

1. H. M. Shizgal, J. Parent. Nutr. 11, 42 S (1987).

2. D. Halliday and A. G. Miller, Biomed. Mass Spectrom. 4, 82 (1977).

3. A. Barrie and W. A. Coward, Biomed. Mass Spectrom. 12, 535 (1985).

4. K. R. Westerterp, W. H. Saris, F. Brouns and F. Ten Hoor, J Appl. Physiol. 65, 53 (1988)

5. W. W. Wong and L. L. Clarke, Eur. J. Clin. Nutr. 46, 69 (1992)
6. T. B. Coplan, J. D. Wildman and J. Chen, Anal. Chem. 63, $910(1991)$

7. R. R. Wolfe, Radioactive and Stable Isotope Tracers in Biomedicine. Wiley, New York (1992).

8. W. D. Van Marken Lichtenbelt and K. R. Westerterp, Br. J. Nutr. 72, 491 (1994).

9. J. M. Bland and D. G. Altman, Lancet 1307 (1986)

10. B. K. Van Kreel, Clin. Chim. Acta 231, 117 (1994). 